\title{
AS POLÍTICAS PÚBLICAS PARA O AUTISMO NO BRASIL, SOB A ÓTICA DA PSICANÁLISE ${ }^{1}$
}

\author{
PUBLIC POLICIES FOR AUTISM IN BRAZIL, FROM THE PSYCHOANALYSIS PERSPECTIVE \\ POLÍTICAS PÚBLICAS PARA EL AUTISMO EN BRASIL, DESDE LA PERSPECTIVA DEL \\ PSICOANÁLISIS
}

Paula Pimenta*

\begin{abstract}
RESUMO
O artigo se propõe a assinalar a transposiçãao para o âmbito das políticas públicas brasileiras da tensão epistêmica existente entre as propostas reeducativas e psicodinâmicas para o tratamento do autismo, identificando a psicanálise nesta última categoria e a terapia cognitivo-comportamental entre as primeiras. Para tanto, apresenta brevemente algumas normas brasileiras que regem a inclusão, nas políticas públicas, das pessoas com autismo. Localiza o foco de seu conteúdo nos dois documentos orientadores para o tratamento do autismo no Sistema Único de Saúde (SUS), lançados pelo Ministério da Saúde em 2013, o que possibilita explicitar a ótica da psicanálise em relação às políticas propostas. O deslocamento da tensão epistêmica para o contexto político, com a decorrente alegação legal de impedimento da psicanálise para atender as pessoas com autismo, é elucidado por alguns fatos históricos recentes, ocorridos tanto na França quanto no Brasil. A metodologia usada é a revisão bibliográfica.
\end{abstract}

Palavras-chave: Autismo. Políticas públicas brasileiras. Psicanálise.

\begin{abstract}
This article aims to highlight the transposition, within the scope of Brazilian public policies, of the existing epistemic tension between the re-educational and psychodynamic proposals for the treatment of autism, identifying Psychoanalysis in the latter category and Cognitive-Behavioral Therapy among the former. Thus, some Brazilian norms that rule the inclusion of people with autism in public policies are briefly presented here. It focus on the content of the two guiding documents for the treatment of autism in the Unified National Health System (SUS), issued by the Ministry of
\end{abstract}

1 Texto elaborado com base no conteúdo das aulas da disciplina Políticas Públicas e Acolhimento Institucional do Autista, ministrada pela autora e pertencente ao Curso de Pós-Graduação Lato Sensu Abordagem Psicanalítica do Autismo e suas Conexôes, ofertado pelo Instituto de Educação Continuada da Pontifícia Universidade Católica de Minas Gerais (PUC Minas). * Doutora em Psicologia, pela Universidade Federal de Minas Gerais (UFMG), com pesquisa voltada para o tema do autismo, professora da Faculdade de Ciências Médicas de Minas Gerais e do curso de Pós-graduação Lato Sensu Abordagem Psicanalítica do Autismo e suas Conexões do IEC-PUC Minas, membro-fundador do Movimento Psicanálise, Autismo e Saúde Pública (MPASP), atual coordenadora do Observatório de Políticas do Autismo da Federação Americana de Psicanálise de Orientação Lacaniana (FAPOL), psicóloga e psicanalista. 
Health in 2013, which makes it possible to explain the perspective of psychoanalysis in relation to the proposed policies. The shift of epistemic tension to the political context, with the consequent legal claim forbidding the psychoanalysis to assist people with autism, is cleared up by some recent historical facts, taking place either in France or in Brazil. The methodology applied was the literature review.

Keywords: Autism. Brazilian public policies. Psychoanalysis.

\section{RESUMEN}

El artículo tiene como objetivo resaltar la transposición al alcance de las políticas públicas brasileñas de la tensión epistémica existente entre las propuestas reeducativas y psicodinámicas para el tratamiento del autismo, identificando el psicoanálisis en la última categoría y la terapia cognitivoconductual entre las primeras. Con este fin, presenta brevemente algunas leyes brasileñas que rigen la inclusión de las personas con autismo en las Políticas Públicas. Encuentra el foco de su contenido en los dos documentos guía para el tratamiento del autismo en el Sistema Único de Salud (SUS), lanzado por el Ministerio de la Salud en 2013, que permite explicar la perspectiva del psicoanálisis en relación con las políticas propuestas. El cambio de la tensión epistémica al contexto político, con la consiguiente afirmación legal de que se impide que el psicoanálisis sirva a las personas con autismo, se aclara por algunos hechos históricos recientes, tanto en Francia como en Brasil. La metodología utilizada es la revisión de la literatura.

Palabras clave: Autismo. Políticas públicas brasileñas. Psicoanálisis.

\section{INTRODUÇÃO}

s políticas públicas voltadas às pessoas com autismo, no Brasil, remontam à Constituição Federal de 1988, em seu artigo 208, inciso III, que 1 garantia o Atendimento Educacional Especializado (AEE) aos alunos com deficiência, preferencialmente na escolarização regular. $O$ texto da Constituição foi reforçado pela legislação que a ele se seguiu, notadamente pela (Lei $n^{\circ} 7.853$, 1989) que estabeleceu "normais gerais que asseguram o pleno exercício dos direitos individuais e sociais das pessoas portadoras de deficiências e sua efetiva integração social", cujo conteúdo foi reiterado pelo artigo 54, inciso III do Estatuto da Criança e do Adolescente (ECA) $\left(\right.$ Lei $n^{\circ}$ 8.069, 1990) e pela Lei de Diretrizes e Bases da Educação Nacional (LDBEN) (Lei no 9.394, 1996).

Em menção direta ao autismo, devemos destacar a Política Nacional de Educação Especial na Perspectiva da Educação Inclusiva (PNEEPEI) (Brasil, 2008), que esclareceu qual seria o público-alvo da educação especial: alunos com 
deficiência, transtornos globais do desenvolvimento (TGD) (em que está incluso o autismo) e altas habilidades/superdotação e a "Lei do Autismo" (Lei no 12.764, 2012), que estabeleceu ser o autismo - ou o transtorno do espectro autista (TEA), para utilizarmos o termo atual - uma deficiência, "para todos os efeitos legais" (Lei $n^{\circ} 12.764,2012$ ). Efetivamente, foi a partir dessa lei que os autistas passaram a ser acolhidos pelas políticas públicas como sujeitos de direitos e as áreas da educação, da saúde e da assistência social (para mencionar as principais) passaram, de fato, a ter de encontrar expedientes para com eles atuar. À Lei do Autismo se seguiram o Decreto $n^{\circ} 8.368 / 2014$ que a regulamentou, tornando obrigatório às escolas regulares de âmbito público recebê-los, e o Estatuto da Pessoa com Deficiência (Lei $n^{\circ}$ 13.146, 2015), que demarcou e pormenorizou os direitos dos deficientes, incluindo-se aí os autistas.

Cada uma dessas leis promoveu um impacto no lugar social das pessoas com autismo, com desdobramentos importantes nas microesferas da prática com esses sujeitos. ${ }^{2}$ Neste artigo, interessa-nos abordar a atuação da psicanálise nas políticas públicas para os autistas, no Brasil, visando ao recorte da possibilidade de manutenção da clínica psicanalítica com esses sujeitos, que se viu ameaçada de existir pela via de algumas ações políticas. Para tanto, faremos uma correlação inicial com a conjuntura semelhante ocorrida na França, no intuito de nos indagar sobre a vigência de um movimento político e epistêmico em prol da hegemonia das abordagens de viés reeducativo no tratamento das pessoas com autismo. Seguindo nesse propósito, destacaremos os dois documentos orientadores para a atuação com as pessoas com autismo no âmbito do SUS, lançados em 2013 pelo Ministério da Saúde (MS), e que demonstram essa tensão entre a proposta reabilitativa para o tratamento do autismo e o consentimento às abordagens psicodinâmicas, que visam à intervenção com base no modo de estar no mundo apresentado pelo autista, rejeitando toda e qualquer postura impositiva do terapeuta.

\section{NA FRANÇA}

Em 2012, Laurent publicou seu livro intitulado $A$ batalha do autismo: da clínica à política (Laurent, 2014). Seu surgimento foi um ato político em resposta à eclosão de um movimento francês para banir legalmente a psicanálise do tratamento das pessoas com autismo.

De fato, no ano anterior, em setembro de 2011, foi lançado, no território francês, o documentário Le mur ( $O$ muro), dirigido por Sophie Robert, que defendia a importância da terapia cognitivo-comportamental (TCC) para os

2 Para saber mais sobre a legislação brasileira sobre o autismo, ver meu artigo Clínica e escolarização dos alunos com transtorno do espectro autista (TEA) (Pimenta, 2019). 
autistas e, em contrapartida, denegria a capacidade da psicanálise em tratá-los. Robert mostrava, em seu filme, uma criança de 11 anos diagnosticada com " $80 \%$ de autismo" (como ela própria se apresenta para o vídeo) e um adolescente de 14 anos "tratado" pela psicanálise em um hospital-dia. O adolescente estava institucionalizado, tendo fala e comportamento extremamente limitados. Já a criança aparentava ser normal, o que era defendido no filme como unicamente decorrente das intervençôes comportamentais por que passou.

Vários psicanalistas foram entrevistados por Robert, sendo indagados, sobretudo, se o autismo era uma psicose e como seria seu tratamento. De fato, as respostas mostradas foram desastrosas, com nenhum deles sendo capaz de diferenciar autismo e psicose (nem mesmo de fundamentar o que os aproximaria) e muito menos indicar a guia de tratamento da psicanálise para o autismo.

O documentário veio na esteira da mobilização das associações de pais franceses, que requeriam a inclusão nos serviços de saúde do país da oferta da TCC para seus filhos. E eram os psicanalistas aqueles que ocupavam os postos por eles desejados. Em decorrência, em 2012, o autismo ganhou o status, na França, de "grande causa nacional" do ano. Com efeito, em 12 de janeiro, foi lançada uma proposta de lei para proibir psicanalistas de tratarem autistas. A indicação não se consolidou legalmente, mas, em 8 de março, a Haute Autorité de la Santé $(\mathrm{HAS})^{3}$ da França publicou um relatório que optava pelo aporte "educativo, comportamental e desenvolvimentista" para o tratamento dos autistas.

Essa pressão política sobre a relação da psicanálise com o autismo, que sempre atendeu os autistas, pois foi a abordagem que historicamente iniciou a prática da clínica com crianças, obrigou os psicanalistas a formalizarem sua atuação clínica com esses sujeitos. Foi nesse contexto que Laurent publicou seu livro sobre a batalha do autismo.

De fato, já se desenrolava, no âmbito universitário, o início dessa formalização. Com base nos testemunhos publicados por autistas de diversos países, que buscavam demonstrar como entendiam e se colocavam no mundo, Maleval (2009) havia organizado o livro L'autiste, son double et ses objets, ${ }^{4}$ publicado no primeiro semestre de 2009, pela coleção Clínica Psicanalítica e Psicopatologia, da Universidade de Rennes. No ano anterior, em 2008, Bonnat havia organizado outro livro, Autisme et psychose: machine autistique et délire machinique: clinique différentielle des psychoses, ${ }^{5}$ publicado pela mesma coleção. Sem contar com diversos artigos de psicanalistas, publicados anteriormente a essas datas, em revistas especializadas de psicanálise. 
A formalização da clínica psicanalítica com autistas foi importante, interna e externamente, à psicanálise. Internamente, fez com que se começasse a traçar o que se faz quando se atua com os autistas e a identificar suas singularidades em relação às psicoses. Externamente, obrigou os psicanalistas a falarem a língua do Outro, a explicitarem seus conceitos para aqueles não iniciados na psicanálise e a argumentarem a favor da direção do tratamento com autistas e, sobretudo, a demonstrar seus efeitos.

A escolha de Laurent pelo termo "batalha" implica com clareza o campo político, mas também o âmbito clínico, pois defende o direito à diversidade de abordagens, em respeito à forma de ser de cada um. "Apenas nessa variedade o trabalho do sujeito pode ter lugar efetivo" (Vieira \& Silva, 2014, p. 11).

\section{NO BRASIL}

Em paralelo ao que ocorria na França, também no Brasil, havia uma mobilização em favor da inclusão da TCC nas políticas públicas para os autistas. Aqui, igualmente o ano de 2012 foi emblemático. Em 4 de setembro, a Secretaria Estadual de Saúde de São Paulo (SES-SP) lançou um edital para credenciar instituiçóes especializadas em atendimento a pacientes com transtorno do espectro autista (TEA), com a ressalva de que tivessem psicólogos especializados em terapia cognitivo-comportamental e fonoaudiólogos especializados em linguagem pragmática. Tal exigência, explícita quanto ao recorte técnico em um edital público, incitou a comunidade científica que reconhecia o lugar das abordagens psicodinâmicas a se posicionar publicamente. Assim, ocorreu a primeira reunião do que se transformou, naquela data de 15 de dezembro de 2012, no Movimento Psicanálise Autismo e Saúde Pública (MPASP). Ele foi composto por psicanalistas de várias correntes, mas também por fonoaudiólogos, psicólogos, psiquiatras, médicos pediatras, neurologistas, terapeutas ocupacionais, psicopedagogos e demais profissionais dos serviços públicos e privados de saúde para a infância e a adolescência, bem como por vários acadêmicos de universidades diversas, de norte a sul do País.

Entre o setembro deflagrador e o dezembro da primeira reunião, houve outra medida pública nessa mesma via, com a tentativa de fechamento do CRIAUnifesp (Centro de Referência da Infância e da Adolescência), na cidade de São Paulo. Quanto ao edital da SES-SP, a mobilização organizada do MPASP conseguiu derrubá-lo, por meio de uma petição pública que recolheu quantidade significativa de assinaturas. 
No encontro de dezembro do MPASP, foi anunciada a consulta pública que viria a acontecer no início de 2013 sobre o documento Linha de cuidado para a atenção às pessoas com transtornos do espectro do autismo e suas famílias na Rede de Atenção Psicossocial do Sistema Único de Saúde, formulado pelo Ministério da Saúde (Brasil, 2015) e de cuja confecção alguns colegas ali presentes participaram.

É importante lembrar que a Lei no $12.764 / 2012$, da Política Nacional de Proteção dos Direitos da Pessoa com Transtorno do Espectro Autista, foi promulgada também em 2012, na data de 27 de dezembro. Ela passou a ser conhecida como "Lei Berenice Piana", em homenagem à mãe que lutou dedicadamente para que ela existisse, ou simplesmente "Lei do Autismo".

Em 26 de janeiro de 2013, houve o segundo encontro do MPASP, já com uma articulação mais consistente entre seus membros e a contratação de uma assessoria jurídica e outra de marketing, que pudessem auxiliar o movimento em suas atuações políticas e de divulgação do trabalho da psicanálise com as pessoas com autismo. Um blog foi criado para esse segundo fim, e artigos temáticos foram escritos em conjunto e publicados. O terceiro encontro do MPASP ocorreu em 23 de fevereiro de 2013 e, em 23 e 24 de março, teve lugar a sua I Jornada, sediada na cidade de São Paulo. Nesse evento, os funcionários do CAPS Itapeva, também de São Paulo, informaram a demissão em massa por que haviam passado, no início do ano.

Como fruto do trabalho conjunto do MPASP, no dia 2 de abril de 2013, data estabelecida pela ONU como Dia Mundial do Autismo, foi lançado seu manifesto, assinado por seus mais de cem membros e por mais tantos que com ele concordavam, e publicado nas principais mídias escritas do país, assim como divulgado digitalmente para diversas instituições do país ligadas ao autismo (de saúde, de educação, associações de pais, órgãos públicos, entre outras).

Foi também nesse 2 de abril de 2013 que foi lançado, pelo Ministério da Saúde, o documento Diretrizes de atenção à reabilitação da pessoa com transtornos do espectro do autismo (TEA) (Brasil, 2014), no lugar do aguardado Linha de cuidado [. . .] (Brasil, 2015). Os membros do MPASP, bastante surpresos com a decisão do MS, viram o Linha de cuidado [. . . ] ser lançado, secundariamente, durante o congresso dos CAPSi (Centros de Atenção Psicossocial InfantoJuvenil), ocorrido no Rio de Janeiro, ao fim do mesmo mês. Diante da existência de dois documentos orientadores para o atendimento das pessoas com autismo na rede de atenção básica de saúde, e por meio das manifestações dos membros do MPASP participantes da construção do Linha de cuidado [. . .], o então ministro da Saúde, Alexandre Padilha, convidou o MPASP para realizar o estudo 
comparativo dos dois documentos, a fim de ver como poderiam se articular efetivamente no atendimento aos autistas na rede pública de saúde.

\section{BREVE CONTEXTUALIZAÇÃO DOS DOIS DOCUMENTOS}

O Linha de cuidado para a atenção integral às pessoas com transtorno do espectro do autismo e suas famílias no Sistema Único de Saúde (Brasil, 2015) traz, em seu âmago, o reconhecimento dos fatores culturais, éticos e políticos envolvidos na questão do diagnóstico do autismo, sustentando a importância de se oferecerem diversas técnicas e métodos clínicos aos autistas e a seus familiares, a fim de que escolham aquele com que mais concordam. As chamadas "abordagens psicodinâmicas", que atentam em compreender o modo do autista estar mundo, suas escolhas por trás de seus comportamentos, foram abrangidas por esse documento.

Por sua vez, o Diretrizes de Atenção à Reabilitação da Pessoa com Transtornos do Espectro do Autismo (TEA) (Brasil, 2014) faz um recorte objetivo e técnico da questão do diagnóstico do autismo e enfatiza, para seu tratamento, o uso de estratégias de habilitação e de reabilitação, visando a desenvolver as habilidades funcionais. Sob essa ótica, esse documento designa o viés reeducativo, não incluindo as abordagens psicodinâmicas como opção para o tratamento do autismo (Oliveira, Feldman, Couto, \& Lima, 2017; Araújo, Veras, \& Varella, 2019).

Ambos os documentos foram elaborados pela Secretaria de Atenção à Saúde (SAS) do Ministério da Saúde. O Linha de cuidado [. . .] (Brasil, 2015) foi elaborado pela Coordenação-Geral de Saúde Mental, Álcool e outras Drogas, inclusa no Departamento de Atenção Especializada e Temática da SAS. O Diretrizes de atenção [. . .] (Brasil, 2014) foi proposto pela CoordenaçãoGeral de Saúde da Pessoa com Deficiência, ligada ao Departamento de Ações Programáticas Estratégicas da SAS.

O grupo de trabalho (GT) que elaborou o Linha de cuidado [. . .] (Brasil, 2015) iniciou sua construção em dezembro de 2011. Ele foi constituído por membros dos departamentos da SAS de Atenção Básica, de Ações Programáticas Estratégicas (incluindo sua Coordenação-Geral de Saúde da Pessoa com Deficiência, a mesma que propôs o Diretrizes de atenção [. . .] ), de Atenção Especializada e Temática (e sua Coordenação-Geral de Saúde Mental, Álcool e outras Drogas), como também por representantes de universidades e da sociedade civil, incluindo-se aí as associaçôes de pais de autistas, bem como por gestores e profissionais da Raps (Rede de Atenção Psicossocial) locais do SUS 
(Sistema Único de Saúde). O GT teve como parceiros as Áreas Técnicas da Saúde da Pessoa com Deficiência, da Saúde da Criança e Aleitamento Materno (ATCAM) e da Rede de Atenção à Urgência e Emergência (RUE), o Ministério da Educação, o Ministério do Desenvolvimento Social e Combate à Fome e a Secretaria Nacional de Promoção dos Direitos da Pessoas com Deficiência. O grupo trabalhou por um ano, de 2011 a 2012, e levou sua proposição final à Consulta Pública, que ficou no ar no site do MS durante os três primeiros meses de 2013, ampliando o diálogo com a sociedade civil e recolhendo contribuições significativas para seu aprimoramento. Tratou-se, verdadeiramente, de um documento democrático.

À mesma época em que o GT do Linha de cuidado... iniciou seu trabalho, em dezembro de 2011, a Coordenação-Geral da Saúde da Pessoa com Deficiência lançou o Viver sem Limites: Plano Nacional de Direitos da Pessoa com Deficiência (Decreto $n^{\circ} 7.612,2011$ ), com base na Convenção Internacional sobre os Direitos da Pessoa com Deficiência, promulgada pelo Estado Brasileiro pelo Decreto no 6.949, de 25 de agosto de 2009. O plano Viver sem Limites é de responsabilidade da Área Técnica da Pessoa com Deficiência. Em abril de 2012, o Ministério da Saúde instituiu a Rede de Cuidados à Saúde da Pessoa com Deficiência no âmbito do SUS (Portaria no 793, 2012). E, em 27 de dezembro de 2012, o governo brasileiro promulgou a Política Nacional de Proteção dos Direitos da Pessoa com Transtornos do Espectro do Autismo (Lei no 12.764, 2012), "Lei do Autismo", pela qual o autista passou a ser considerado pessoa com deficiência, "para todos os efeitos legais", como visto acima.

O documento Diretrizes de atenção [. . .] (Brasil, 2014) é fruto dessa política instituída internamente na Coordenação-Geral da Saúde da Pessoa com Deficiência, tendo sido elaborado por técnicos do Ministério da Saúde, por representantes da sociedade civil (associaçôes de pais de autistas) e por pesquisadores especialistas na área, em um curto período e não tendo sido disponibilizado à consulta pública.

No ano seguinte à divulgação dos dois documentos, surgiu o Decreto $\mathrm{n}^{\mathrm{o}}$ 8.368/2014, que teve o propósito de regulamentar a Lei no $12.764 / 2012$. Ele instituiu como base para o TEA o CID-10 (Classificação Internacional de Doenças, da Organização Mundial de Saúde) e a CIF (Classificação Internacional de Funcionalidade, Incapacidade e Saúde), abarcando tanto os parâmetros da saúde mental quanto os da reabilitação como referências para o diagnóstico.

Como elemento novo no cenário das políticas públicas para o autismo, o Diretrizes de atenção [. . . (Brasil, 2014) criou os CER (Centros Especializados de Reabilitação), aprimorado pelo decorrente Documento Instrutivo de 
Reabilitação Auditiva, Física, Intelectual e Visual (CER e serviços habilitados em uma única modalidade). Em termos práticos, por meio dessa diretriz, as APAE se transformaram em CER e passaram a ser especializadas em reabilitar de um a quatro tipos de deficiências, sendo, desse modo, classificadas em CER I, CER II, CER III ou CER IV. O autismo passou a ser acoplado à deficiência intelectual (DI), nessa categorização: CER especializado em "deficiência intelectual e autismo".

O desafio que restou lançado foi o de fazer as ações propostas pelos dois documentos se articularem entre si e a outros pontos de atenção da Rede SUS (Atenção Básica, Especializada e Hospitalar), bem como aos serviços de proteção social (Centros-Dia, Residências Inclusivas, CRAS e CREAS) e de educação.

Foi nessa vertente que ocorreu, em 3 de julho de 2013, a reunião do Comitê de Assessoramento do MS, do qual três componentes do MPASP participaram, com a intenção de se conseguir fazer implementar a Política Pública de Atenção ao Autismo, procurando articular os campos da reabilitação e da atenção psicossocial.

Em atenção ao pedido inicial do Ministro da Saúde, em 15 de maio de 2014, o MPASP (2014) entregou seu estudo comparativo entre os dois documentos lançados pelo MS para o autismo, finalizado dois meses antes, em março, para o então atual ministro da pasta, Arthur Chioro.

Nesse ínterim, vale ressaltar algumas intervenções políticas do MPASP que tiveram um alcance importante. Em agosto de 2013, houve a transmissão, pelo programa Fantástico da Rede Globo de Televisão, de quatro episódios sobre o diagnóstico e o tratamento do autismo, no qual o recorte apresentado foi tendenciosamente reeducativo e nada se falou dos recursos presentes na rede pública de saúde. Em razão disso, o MPASP lançou um documento público de repúdio à restrição de abordagens clínicas e de informações a respeito do atendimento no SUS, apresentada no programa. Ainda nesse mesmo mês de agosto, a SES-SP lançou novo edital para credenciamento de instituições, nos moldes do anterior de 2012. O MPASP se articulou para barrá-lo.

\section{COMPARATIVO DE ALGUNS PONTOS-CHAVE DOS DOIS DOCUMENTOS}

Quanto aos objetivos explicitados por cada documento, o Linha de cuidado... (Brasil, 2015) busca garantir ressonância e articulação entre todas as redes de interface para o cuidado das pessoas com TEA e suas famílias, ressaltando o cuidado nas RAPS, incluindo-se os CAPS e CAPSi. Já o Diretrizes de atenção [. 
.. (Brasil, 2014) propõe articular a atenção na Rede de Cuidados à Pessoa com Deficiência, de onde participam os CER.

Quanto à relação que estabelecem entre TEA e deficiência intelectual, o Linha de cuidado [. . .] (Brasil, 2015) busca diferenciá-los, mas faz uma ressalva. Afirma que a DI tem início precoce, mas não apresenta a gama de limitações na interação, na comunicação e no repertório de interesses como ocorre no TEA. No entanto, uma DI grave pode apresentar características autistas, incorrendo na classificação diagnóstica do CID 10 como F 84-1, "autismo atípico". O Diretrizes de atenção [. . .] (Brasil, 2014) não busca diferenciá-los e ainda os acopla na mesma modalidade de reabilitação.

Sobre a deteç̧ão precoce do TEA, ambos os documentos consideram importante a detecção precoce dos sinais de risco para o TEA, com uso de instrumentos. E aí se percebe uma diferença de concepção sutil e condizente com o escopo epistêmico que embasou cada documento: o Linha de cuidado [. . .] (Brasil, 2015) concebe os sinais de risco encontrados como possibilidade de incorrer em TEA, sem que esse diagnóstico possa ser conclusivo nesse momento (o que não impede a necessidade de atuação precoce dos profissionais na tentativa de restabelecer os índices normais do desenvolvimento psicossocial do bebê); o Diretrizes de atenção... (Brasil, 2014) já os distingue como preditores de TEA, na via da afirmação do diagnóstico em uma idade bem precoce.

Quanto ao fluxo de atenção, ambos demarcam a importância do atendimento em rede. Mas a direção do fluxo não se encontra estabelecida a priori. Não indicam como se dará a articulação entre a RAPS, da alçada da CoordenaçãoGeral de Saúde Mental, Álcool e outras Drogas, e a Rede de Atenção à Pessoa com Deficiência, gerenciada pela Coordenação-Geral da Saúde da Pessoa com Deficiência.

Como aspectos dignos de nota, o Linha de cuidado [. . .] (Brasil, 2015) busca ressaltar o termo inglês disability (em tradução livre, "desabilidade"), que é usado para se referir às dificuldades do TEA, no lugar do "déficit". (Pereira et al., 2016). A "desabilidade" diria mais de uma dificuldade funcional de colocar em ação algumas intenções e menos de uma incapacidade inata de realizá-las. Desse modo, o documento aponta que "ainda que o funcionamento intelectual da pessoa com autismo tenha suas particularidades, a sua desabilidade não é cognitiva, está centrada de maneira determinante no encontro com o outro" (Movimento Psicanálise, Autismo \& Saúde Pública, 2014). E acrescenta que a condição cognitiva da pessoa com autismo, seja ela maior ou menor que uma suposta média, não é o que causa o autismo, muito pelo contrário, é consequente ao modo que esse sujeito encontrou de estar no mundo com os outros. Essa 
perspectiva faz uma transposição da concepção de um modelo biomédico, em que se estabelece uma relação de causalidade e de dependência lineares (por exemplo: entre impedimentos corporais e desvantagens sociais) para a noção de relação e interdependência entre os aspectos biológicos e sociais.

O mesmo documento busca definir a noção de "subjetividade", indicando que é o acontecimento que se dá no encontro entre um corpo (em qualquer condição de desenvolvimento) e a cultura no qual este corpo se insere (Movimento Psicanálise, Autismo \& Saúde Pública, 2014). Nesse viés, reafirma "a multifatorialidade causal e etiológica do autismo", ao passo que o Diretrizes de atenção [. . .] (Brasil, 2014) conceitua o autismo como uma "síndrome neuropsiquiátrica".

\section{CONSIDERAÇŌES FINAIS}

A proposta do Linha de cuidado [. . .] (Brasil, 2015) coaduna-se com a aposta da política da psicanálise para os autismos. É pela via da multifatorialidade que se pode conceber a recomendação da diversidade de abordagens e técnicas para o tratamento do espectro do autismo. As famílias devem ter liberdade de escolha, por terem papel fundamental no projeto terapêutico singular (PTS) do membro com autismo.

A psicanálise não descarta a via educativa para esses sujeitos, que muito têm a se beneficiar com as conquistas cognitivas que proporcionam. As aprendizagens são importantes e oportunas como possibilidade para a interação social desses indivíduos e para a aquisição de recursos para lidar com o mundo. No entanto há concepções diferenciadas do que seja a aprendizagem para a pessoa com autismo e dos processos pedagógicos a ela pertinentes. Para a psicanálise, qualquer intervenção que exclua o sujeito que lá está se mostra em desacordo com seus princípios éticos. Conseguir obter o consentimento do autista à interação social é um desafio. Nada impossível, no entanto, quando colocamos sua singularidade no centro da discussão, buscando compreender o que estaria fundamentando seus comportamentos estranhos e repetitivos, para que, em um verdadeiro trabalho de equipe, com a manutenção do saber de cada área, possamos atuar guiados pelo autista e por suas invenções.

A batalha não é pela psicanálise em detrimento de outras abordagens, a batalha é pela diversidade das ofertas de tratamento, o que faz do Linha de cuidado [. . .] (Brasil, 2015) o documento que converge a política da psicanálise para o autismo com o que foi traçado pelas políticas públicas brasileiras para esse fim. 
O que se vê, em termos gerais, é a transposição para o âmbito das políticas públicas da histórica tensão clínico-epistêmica existente entre as propostas reeducativas e psicodinâmicas para o tratamento do autismo. O deslocamento dessa querela para o contexto político, com a decorrente alegação legal de impedimento da psicanálise para atender as pessoas com autismo, foi e deve ser, sempre, interditado. A TCC deve, sim, ter seu lugar junto às pessoas com autismo, seguindo a guia do que recomenda o Linha de cuidado[. . .] (Brasil, 2015), mas não como imposição legal que implica, de outro lado, a proibição de atuação a outro tipo de abordagem, qualquer que seja ele. Afinal, cabe à família conhecer a variabilidade de ofertas e optar pelo método de tratamento para o membro com autismo, sob a prerrogativa da liberdade de escolha compreendida em todo processo democrático. 


\section{REFERÊNCIAS}

Araújo, J., Veras, A., \& Varella, A. (2019, janeiro-abril). Breves considerações sobre a atenção à pessoa com transtorno do espectro autista na Rede Pública de Saúde. Revista Psicologia e Saúde, 11(1), 89-98.

Bonnat, J. L. (Org.) (2008). Autisme et psychose: machine autistique et délire machinique: clinique différentielle des psychoses. Rennes: Presses Universitaires de Rennes. (Clinique Psychanalytique et Psychopathologie).

Brasil. (2008, janeiro). Política Nacional de Educação Especial na Perspectiva da Educação Inclusiva. Brasília: Ministério da Educação, Secretaria de Educação Especial. Recuperado a partir de http://portal.mec.gov.br/arquivos/pdf/politicaeducespecial.pdf

Brasil. (2014). Diretrizes de atenção à reabilitação da pessoa com transtornos do espectro do autismo (TEA). Brasília: Ministério da Saúde, Secretaria de Atenção à Saúde, Departamento de Ações Programáticas Estratégicas. (Documento original datado de 2013).

Brasil. (2015). Linha de cuidado para a atenção às pessoas com transtornos do espectro do autismo e suas famílias na Rede de Atenção Psicossocial do Sistema Unico de Saúde. Brasília: Ministério da Saúde, Secretaria de Atenção à Saúde, Departamento de Atenção Especializada e Temática. (Documento original datado de 2013).

Constituição da República Federativa do Brasil (1988). (1988). Brasílias: Supremo Tribunal Federal. Recuperado a partir de http://www.stf.jus.br/arquivo/cms/legislacaoConstituicao/anexo/CF.pdf

Decreto $\mathrm{n}^{\circ}$ 6.949, de 25 de agosto de 2009. (2009, 25 agosto). Promulga a Convenção Internacional sobre os Direitos das Pessoas com Deficiência e seu Protocolo Facultativo, assinados em Nova York, em 30 de março de 2007. Diário Oficial da União, Brasília. Recuperado a partir de http://www.planalto.gov.br/ccivil_03/_ato2007-2010/2009/decreto/d6949. htm

Decreto $\mathrm{n}^{\mathrm{o}}$ 7.612, de 17 de novembro de 2011. (2011, 17 novembro). Institui o Plano Nacional dos Direitos da Pessoa com Deficiência - Plano Viver sem Limite. Diário Oficial da União, Brasília. Recuperado a partir de http://www.planalto.gov.br/ccivil_03/_Ato2011-2014/2011/Decreto/ D7612.htm 
Decreto no 8.368, de 2 de dezembro de 2014. (2014, 2 novembro). Regulamenta a Lei no 12.764 , de 27 de dezembro de 2012, que institui a Política Nacional de Proteção dos Direitos da Pessoa com Transtorno do Espectro Autista. Diário Oficial da União, Brasília. Recuperado a partir de http://www.planalto.gov.br/ccivil_03/_ato2011-2014/2014/decreto/d8368. htm

Laurent, É. (2014). A batalha do autismo: da clínica à política. Rio de Janeiro: Zahar.

Lei no 7.853, de 24 de outubro de 1989. (1989, 24 outubro). Dispõe sobre o apoio às pessoas portadoras de deficiência, sua integração social, sobre a Coordenadoria Nacional para Integração da Pessoa Portadora de Deficiência - Corde, institui a tutela jurisdicional de interesses coletivos ou difusos dessas pessoas, disciplina a atuação do Ministério Público, define crimes, e dá outras providências. Diário Oficial da União, Brasília. Recuperado a partir de http://www.planalto.gov.br/ccivil_03/Leis/L7853.htm

Lei no 8.069, de 13 de julho de 1990. (1990, 13 julho). Dispõe sobre o Estatuto da Criança e do Adolescente e dá outras providências. Brasília: Presidência da República. Diário Oficial da União, Brasília. Recuperado a partir de http://www.planalto.gov.br/Ccivil_03/leis/L8069.htm

Lei $\mathrm{n}^{\circ}$ 9.394, de 20 de dezembro de 1996. (1996, 20 dezembro). Estabelece as diretrizes e bases da educação nacional. Diário Oficial da Uniāo, Brasília. Recuperado a partir de http://www.planalto.gov.br/ccivil_03/leis/19394.htm

Lei $\mathrm{n}^{\circ}$ 12.764, de 27 de dezembro de 2012. (2012, 27 dezembro). Institui a Política Nacional de Proteção dos Direitos da Pessoa com Transtorno do Espectro Autista; e altera o $\$ 3^{\circ}$ do art. 98 da Lei ${ }^{\circ}$ 8.112, de 11 de dezembro de 1990. Diário Oficial da União, Brasília. Recuperado a partir de http://www.planalto.gov.br/ccivil_03/_ato2011-2014/2012/lei/112764.htm

Lei no 13.146, de 6 de julho de 2015. (2015, 6 julho). Institui a Lei Brasileira de Inclusão da Pessoa com Deficiência (Estatuto da Pessoa com Deficiência). Diário Oficial da União, Brasília. Recuperado a partir de http://www.planalto.gov.br/ccivil_03/_ato2015-2018/2015/lei/113146.htm

Maleval, J.-C. (Org.). (2009). L'autiste, son double et ses objets. Rennes: Presses Universitaires de Rennes. (Clinique Psychanalytique et Psychopathologie). 
Movimento Psicanálise, Autismo e Saúde Pública/MASP. (2014, maio). Observatório internacional: politicas do autismo: documentos do MS produzidos pelo MPASP. São Paulo: Escola Brasileira de Psicanálise. Recuperado a partir de http://autismoepsicanalise.blogspot.com/2015/02/observatoriointernacional-politicas-do_12.html

Oliveira, B., Feldman, C., Couto, M. C., \& Lima, R. (2017). Políticas para o autismo no Brasil: entre a atenção psicossocial e a reabilitação. Physis, Revista de Saúde Coletiva, 27(3), 707-726.

Pereira, C., Mascarenhas, C., Pisaneschi, É., Araújo, G., Amâncio, L., \& Katz, I. (2016, julho-dezembro). Construçōes e comentários sobre os documentos Linha de Cuidado para a Atenção das Pessoas com Espectro Autista e suas Famílias na Rede de Atenção Psicossocial do Sistema Único de Saúde/SUS e Diretrizes de Atenção à Reabilitação de pessoas com Transtorno do Espectro do Autista (TEA). Analytica, 9(5), 31-40.

Pimenta, P.R.(2019). Clínicae escolarização dos alunos com transtornodo espectro autista (TEA). Educação \& Realidade, 44(1), e84859. Recuperado a partir de http://www.scielo.br/scielo.php?script=sci_arttext $\&$ pid $=S 2175$ 62362019000100205\&lng=pt\&nrm=iso\&tlng=pt

Portaria no 793, de 24 de abril de 2012. Institui a Rede de Cuidados à Pessoa com Deficiência no âmbito do Sistema Único de Saúde. Brasília: Ministério da Saúde. Recuperado a partir de https://bvsms.saude.gov.br/bvs/saudelegis/gm/2012/prt0793_24_04_2012. html

Vieira, M. A., \& Silva, R. F. (2014). Nota ao leitor brasileiro. In É. Laurent, $A$ batalha do autismo: da clínica à política. (pp. 9-14). Rio de Janeiro: Zahar. 